\title{
Modulation of Doxorubicin Actions in Hepatocellular Carcinoma Cells by Insulin-Like Growth Factor-I
}

Maria Grazia Refolo ${ }^{1}$, Rosalba D’Alessandro ${ }^{1}$, Catia Lippolis ${ }^{1}$, Nicola Carella ${ }^{1}$, Caterina Messa ${ }^{1}$, Aldo Cavallini ${ }^{1}$ and Brian Irving Carr ${ }^{2 *}$

${ }^{1}$ Laboratory of Cellular and Molecular Biology, Department of Clinical Pathology, National Institute for Digestive Diseases, IRCCS “Saverio de Bellis”, Via Turi 27, 70013, Castellana Grotte, BA, Italy

${ }^{2}$ Program for Targeted Experimental Therapeutics, Izmir Biomedicine and Genome Center, Dokuz Eylul University, Izmir, Turkey

\begin{abstract}
Hepatocellular carcinoma ( $\mathrm{HCC}$ ) is typically advanced at presentation and doxorubicin is the chemotherapeutic agent most frequently used in chemoembolization. Tumor microenvironment contains many cell types, including platelets, as well as cytokines and growth factors, potentially capable of modulating doxorubicin actions. Insulin-like growth factor I (IGF1) and its receptor (IGF1-R) signaling is important in cellular proliferation and prevention of apoptosis and the acquisition of chemotherapy resistance. IGF1 is present in platelets, which have been shown to alter doxorubicin actions in HCC cells. The effects on growth and motility after IGF1 pre-treatment in doxorubicin-treated HCC cells were thus examined, as well as the IGF1-R downstream pathways, PI3/Akt and MAPK kinases. We found that IGF1 antagonized the doxorubicin-mediated decrease in cell growth and motility, as well as the doxorubicin-mediated decrease in levels of the proliferation-associated proteins phospho-IGF1-R, phospho-ERK, phospho-p38 and phospho-STAT3. The simultaneous induction of PI3K/Akt pathway, mediated by IGF1 receptor, regulated an increase in levels of Bcl-2, Bcl$\mathrm{xL}$ and survivin through the Akt activation. Furthermore, PI3K/Akt signaling modulated several downstream targets, including phosphorylation levels of 4EB-P1, p70S6K and GSK-3ß.
\end{abstract}

Up-regulated IGF1 signaling antagonized the doxorubicin-mediated changes cell proliferation, motility and apoptosis, thus contributing to drug resistance. Therefore IGF1-R may be a promising target for HCC management.

Keywords: Drug resistance; IGF1; PI3K/Akt pathway; Intracellular signaling; Doxorubicin

\section{Introduction}

Doxorubicin, an anthracycline antibiotic with anti-proliferative and cytostatic effects, is widely used in the treatment of inoperable hepatocellular carcinoma (HCC) patients, especially as part of chemoembolization procedures. Despite its high efficacy, the doxorubicin-based chemotherapy is associated with multiple and severe side effect to non-tumors tissues, especially in heart, liver and kidney, restricting its clinical application. Furthermore, several studies have demonstrated that drug resistance decreases susceptibility to chemotherapeutic agent effectiveness [1-3]. We previously reported that platelets and their products, as major components of the HCC microenvironment, could affect cell growth and motility of HCC cells, thus modulating doxorubicin actions [4]. The role of increased blood platelet counts in various clinical aspects and prognosis of HCC has been recently shown $[5,6]$. In particular, it has also been reported that several growth factors have anti-apoptotic action and are able to antagonize doxorubicin-mediated growth inhibition and apoptosis and autophagy induction [7-11].

Among these products, insulin-like growth factor 1 (IGF1) and its receptor (IGF1-R) signaling has been increasingly seen to be important in hepatocarcinogenesis. The IGF1-R signaling triggered by IGF1 is involved in cellular proliferation, cell cycle progression and in the prevention of apoptosis, leading to the maintenance of the tumorigenic phenotype [11,12]. Moreover over-expression of IGF1-R has been demonstrated to reduce the dependence of the tumor cell growth from IGF1 and the cellular susceptibility to apoptosis [12]. It was also recently shown that IGF signaling is involved in the acquisition of chemotherapy resistance associated with several events including altered apoptotic signaling, induction of anti-apoptotic protein and over-expression of multidrug resistance (MDR) gene protein Pgp
$[1,12]$. Therefore, chemotherapy combined with modulation of the IGF1-R pathway may be beneficial in human liver cancer therapy $[12,13]$.

In the present study we have examined the mechanisms underlying the interference of doxorubicin with the two major intracellular pathways induced by IGF1-R, PI3K/Akt and MAPK, in human HCC cell lines.

\section{Materials and Methods}

\section{Cells and drugs}

Doxorubicin was purchased from Pfizer Labs (NY, USA), dissolved in $0.9 \%$ of $\mathrm{NaCl}$ and diluted in the appropriate concentrations. Recombinant human IGF1 was purchased from Prospec (Ness Ziona, Israel), GSK1838705A from Selleckchem (Houston, TX, USA). PLC/PRF/5 and HepG2 human HCC cells were purchased from the American Type Culture Collection (ATCC, Rockville, MD, USA). The culture medium was Dulbecco's Modified Eagle's Medium (DMEM). All cell culture components were purchased from Sigma- Aldrich (Milan, Italy).

*Corresponding author: Brian I Carr, Visiting Professor, Program for Targeted Experimental Therapeutics, Izmir Biomedicine and Genome Center, Dokuz Eylu University, Izmir, Turkey, Tel: +1 412980 4518; Email: brianicarr@hotmail.com

Received: January 23, 2016; Accepted: March 10, 2016; Published March 14 2016

Citation: Refolo MG, D'Alessandro R, Lippolis C, Carella N, Messa C, et al (2016) Modulation of Doxorubicin Actions in Hepatocellular Carcinoma Cells by Insulin-Like Growth Factor-I. Biochem Anal Biochem 5: 256. doi:10.4172/21611009.1000256

Copyright: @ 2016 Refolo MG, et al. This is an open-access article distributed under the terms of the Creative Commons Attribution License, which permits unrestricted use, distribution, and reproduction in any medium, provided the original author and source are credited. 


\section{Cell culture}

HepG2 and PLC/PRF/5 cell lines were cultured in DMEM in monolayer culture, and supplemented with $10 \%$ fetal bovine serum (FBS), $100 \mathrm{U} / \mathrm{ml}$ penicillin, $100 \mu \mathrm{g} / \mathrm{ml}$ streptomycin, and incubated at $37^{\circ} \mathrm{C}$ in a humidified atmosphere containing $5 \% \mathrm{CO}_{2}$ in air. Since $\mathrm{PLC} / \mathrm{PRF} / 5$ cells express high affinity IGF1-R which may mediate the stimulatory effects of exogenous IGF1 [14], we chose to represent the proliferation results in both cell lines and all the subsequent experiments in PLC/PRF/5.

\section{IGF1 assay}

Human Platelet Lysates (hPLs), obtained as previously described [4], was used for the in vitro quantitative determination of human IGF1 by the human IGF1 ELISA kit (Wuhan Boster Biological Technology LTD, Wuhan, China). Serial dilutions of hPL or FBS, used as control, were prepared and processed according to the user's guide.

\section{Proliferation and apoptosis}

The cells were cultured in 1\% FBS medium containing IGF1 40ng/ $\mathrm{ml}$, the concentration was derived from the IGF1 ELISA dosage in hPLs, or hPLs corresponding to $3.75 \times 10^{7}$ platelets $/ \mathrm{ml}$, or equivalent concentration of FBS, in presence of 0.1 and $1 \mu \mathrm{M}$ of doxorubicin. In the same condition HCC cell lines were cultured in presence of IGF1-R inhibitor $1 \mu \mathrm{M}$ GSK1838705A. After a defined time of incubation, the proliferative response was estimated by colorimetric 3-(4,5 dimethylthiazol-2-yl)-2,5-diphenyltetrazolium bromide (MTT) test. The trypan blue exclusion test was used to evaluate cell viability. Each experiment was performed in triplicate and repeated three times.

The Muse Annexin V/Dead Cell Assay Kit (Millipore, Darmstadt, Germany) for quantitative analysis of live, early/late apoptotic and dead cells was used with a Muse Cell Analyzer (Millipore). Briefly, the assay utilizes Annexin V to detect PS on the external membrane of apoptotic cells. A dead cell marker (7-AAD) is also used. HepG2 cell line, including positive and negative controls, were cultured in $1 \%$ FBS medium in presence of doxorubicin 0.1 or $1 \mu \mathrm{M}$ alone (control cells) or in combination with 40ng/ml IGF1 with/without $1 \mu \mathrm{M}$ GSK1838705A. The cells were then processed as described in the user's guide.

\section{Migration and invasion assays}

A scratch assay was performed as previously described $[15,16]$. Briefly, a wound was generated with a pipette tip the on cells grown until it reaches confluence in multiwell plates, after rinsing, medium containing 40ng/ml IGF1 or 1\% FBS (control) alone or in combination with 0.1 or $1 \mu \mathrm{M}$ of doxorubicin with/without $1 \mu \mathrm{M}$ GSK1838705A. Photographs were taken of each well immediately (T0) and after $24 \mathrm{~h}$ (T1), 48h (T2) and 72h (T3). The values were expressed as percentage of migration, with $100 \%$ being when the wound was completely closed. The results were representative of three independent experiments.

Cell invasion assays were performed using Matrigel (BD Transduction, San Jose, CA, USA)-coated Transwells ( $8 \mu \mathrm{m}$ pore PET membrane, Millipore, Billerica, MA, USA) as previously described [16]. Briefly, 0.1 or $1 \mu \mathrm{M}$ of doxorubicin-treated cells were suspended in low serum medium. Medium containing 40ng/ml IGF1 or FBS with/ without $1 \mu \mathrm{M}$ GSK1838705A was added to the bottom wells. After incubation of $24 \mathrm{~h}$, the invading cells were fixed and stained. The images were acquired and analyzed counting the cells with Image J Software (National Institute of Health, USA). Values obtained were expressed as percentage of invading cells, setting the cell counts of control cells as $100 \%$. Results were representative of three independent experiments.

\section{Western blots}

PI3K/Akt signaling and apoptosis markers in cells treated with doxorubicin $1 \mu \mathrm{M}$ alone or in combination with $40 \mathrm{ng} / \mathrm{ml}$ IGF1, with/ without $1 \mu \mathrm{M}$ GSK1838705A, were analyzed by Western Blots as previously described [16]. Briefly, cells were washed twice with cold PBS and then lysed in RIPA buffer (Sigma-Aldrich, Milan; Italy). After quantization of protein concentration, equal amount of protein $(50 \mu \mathrm{g})$ were resolved on SDS-PAGE and transferred to polyvinyldifluoride (PVDF) filters. The blots were blocked with $5 \%(\mathrm{w} / \mathrm{v})$ nonfat dry milk for $2 \mathrm{~h}$ at room temperature and then probed with primary antibody overnight at $4^{\circ} \mathrm{C}$. The primary antibodies were directed against the following proteins: IGF1-R, PI3K and phospho-PI3K (P-PI3K tyr458/tyr199), Akt and phospho-Akt (P-Akt thr308), GSK-3 $\beta$ and phospho-GSK-3 $\beta$ (P-GSK-3 $\beta$ ser9), phospho-4EBP (P-4EBP), p70S6K and phospho-p70S6K (P-p70S6K tyr389), ERK and phospho-ERK (P-ERK thr202/tyr204), p38 and phospho-p38 (P-p38 thr180/tyr182), STAT3 and phospho-STAT3(P-STAT3 ser727), Bax, Bad, Bid, Bcl2, Bcl-xL, survivin and $\beta$-actin (Cell Signaling, Beverly, MA, USA). After three washes, incubation was followed by the reaction with horseradish peroxidase-conjugated secondary antibody for $1 \mathrm{~h}$ at room temperature. The immunoreactive bands were visualized and analyzed using enhanced chemiluminescence detection reagents, according to the manufacturer's instructions, and chemiluminescence detection system (ChemiDoc XRS apparatus and software, Bio-Rad).

The densitometric analysis was expressed as target protein/actin ratio for IGF1-R, P-4EBP, Bax, Bad, Bid, Bcl-2, Bcl-xL and survivin, while for the remaining proteins as the phospho-protein/total protein ratio.

\section{Statistical analysis}

GraphPad Prism 5.0 software (La Jolla, CA, USA) was used for all statistical analysis. Mann-Whitney nonparametric test was employed to assess the statistical significance of differences between two groups. $P<0.05$ was considered statistically significant. All experiments were done in triplicate and data are presented as mean \pm standard deviation (SD).

\section{Results}

\section{IGF1 role in doxorubicin-mediated inhibition of HCC cell} growth

We previously reported that doxorubicin could mediate growth inhibition, migration and invasion in HCC cells [4]. We now examined whether hPL, a key component of the microenvironment and itself stimulant of HCC growth [17], might modify doxorubicin actions.

HCC cells that had been pre-treated for $48 \mathrm{~h}$ with hPLs corresponding to $3.75 \times 10^{7}$ platelets $/ \mathrm{ml}$, or an equivalent concentration of FBS (controls), were cultured for the next $24 \mathrm{~h}$ in presence of doxorubicin $(0.1$ and $1 \mu \mathrm{M})$. We found that doxorubicin-mediated growth inhibition was antagonized by an average of $30 \%(0.1 \mu \mathrm{M}$ doxorubicin) or $55 \%$ ( $1 \mu \mathrm{M}$ doxorubicin) when the cells received hPLs pre-treatment (Figures 1A-1B). In the same experimental conditions, the protective role of $40 \mathrm{ng} / \mathrm{ml}$ IGF1, a potent HCC mitogen that is found in platelets was next tested. The doxorubicin-mediated growth inhibition was decreased by an average of $36 \%(0.1 \mu \mathrm{M}$ doxorubicin $)$ or $48 \%$ (1 $1 \mu \mathrm{M}$ doxorubicin) when the cells received IGF1 pre-treatment (Figures 1C-1D). The effects of both hPLs and IGF1 (Figures 1A-1D) were strongly antagonized by GSK1838705A, an inhibitor of IGF1-R. GSK1838705A was used at a non-toxic concentration $(1 \mu \mathrm{M})$ that did 
not affect the proliferation by itself. The effects of GSK1838705A on hPLs thus provide evidence for the protective effects of hPLs to be mediated by IGF1.

\section{IGF1 role on doxorubicin-mediated induction of apoptosis}

We next investigated the protective role of IGF1 on doxorubicinmediated apoptosis, using the same experimental conditions as for the growth experiments. Doxorubicin caused an increase (about $22 \%$ and $51 \%$ respectively, at either 0.1 or $1 \mu \mathrm{M}$ ) in cellular Annexin V compared with untreated cells $(11 \%)$. When HCC cells were pre-treated with IGF1, a significant decrease in doxorubicin-mediated apoptosis induction was found $(19 \%$ and $23 \%$ respectively, for doxorubicin 0.1 or $1 \mu \mathrm{M})$. Moreover the IGF1 blocking action was abrogated by concomitant addition to the cultures of IGF1 receptor inhibitorl $\mu \mathrm{M}$ GSK1838705A (Figure 2A). These findings were confirmed by Western Blot analysis in which the expression levels of apoptosis inducers (Bax, $\mathrm{Bad}, \mathrm{Bid}$ ) and suppressors (Bcl-2, Bcl-xL, survivin) were evaluated. As shown in Figures 2B-2C, the levels of anti-apoptotic markers were decreased using doxorubicin, compared to the untreated control cells. This effect was antagonized by IGF1 pre-treatment, which caused an increase in all the apoptosis suppressors that were analyzed. The balance between pro and anti-apoptotic factors, expressed as $\mathrm{Bax} / \mathrm{Bcl}$ 2 protein ratio, indicated that the induction of apoptosis observed in doxorubicin-treated cells was counteracted by IGF1 pre-treatment. The specificity of this IGF1 action was shown by using $1 \mu \mathrm{M}$ GSK1838705A which significantly blocked the IGF1 actions.
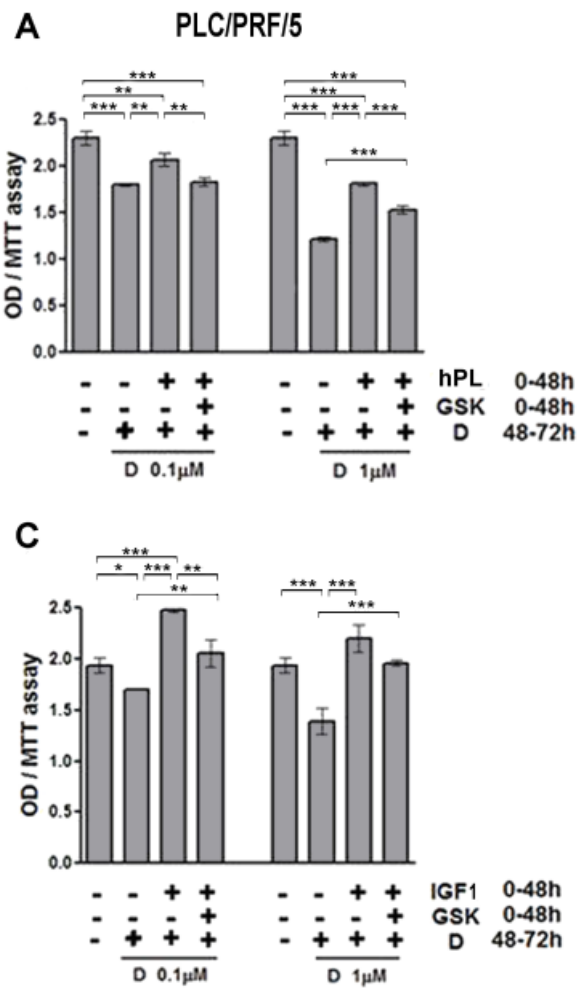

\section{IGF1 antagonism of doxorubicin-mediated inhibition of cell migration and invasion}

IGF1 has been shown to stimulate cell motility $[18,19]$. The protective role of IGF1 on cell migration and invasion was then examined, under the same experimental conditions used in the growth experiments. We found that doxorubicin inhibited cell motility in a reversible manner at low concentrations $(0.1 \mu \mathrm{M})$, at which IGF1 exerted a strong protective effect if added before doxorubicin, but only partially reversed the doxorubicin-mediated inhibition if added after drug treatment (supplementary information 1A-1B). Conversely high doxorubicin concentration $(1 \mu \mathrm{M})$ irreversibly inhibited cell migration and invasion and IGF1 showed only a protective effect (Figure 3A). Comparable results were also obtained with cell invasion (Figure 3B) assays. We also found that IGF1 effects on cell motility were abrogated by the IGF1 receptor antagonist GSK1838705A.

\section{Changes in PI3K/Akt and MAPK signaling}

We examined the levels of total and phosphorylated proteins involved in PI3K/Akt and MAPK signaling by Western Blot analysis, since these are known targets of doxorubicin action, using cells without or with IGF1 pre-treatment.

We found that doxorubicin decreased cellular IGF1-R levels and this decrease was blocked by IGF1 pre-treatment of the cells (Figure $4 \mathrm{~A})$. The results were similar for the phosphorylation levels of PI3K and Akt proteins and for those of 4EB-P1, p70S6K and GSK-3 $\beta$, some of the principal downstream targets of Akt (Figure 4B). In parallel,

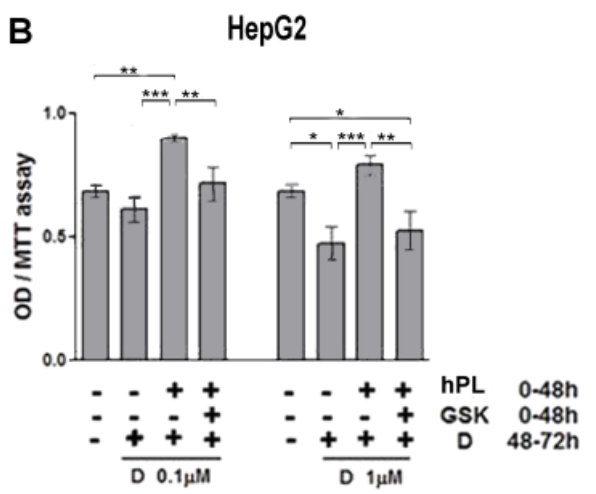

D

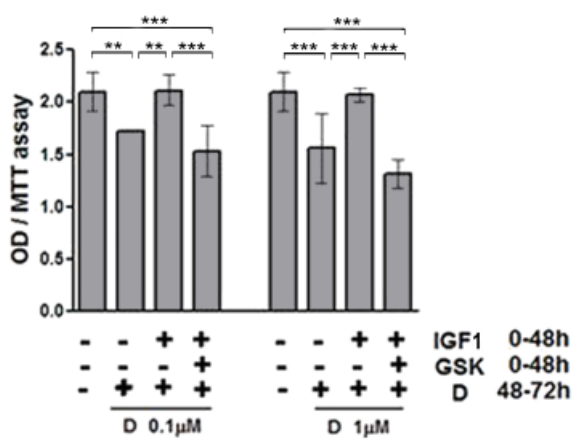

A-B. PLC/PRF/5 and HepG2 cells pre-treated for $48 \mathrm{~h}$ with hPLs corresponding to $3.75 \times 10^{7}$ platelets/ml or FBS (controls) $+/-1 \mu \mathrm{M}$ GSK1838705A, were subsequently cultured for the next $24 \mathrm{~h}$ in presence of two different concentrations of doxorubicin (D $0.1 \mu \mathrm{M}$ and $1 \mu \mathrm{M})$. C-D. In the same experimental condition $40 \mathrm{ng} / \mathrm{ml}$ IGF1, instead of hPLs, was tested. MTT assay was assessed after $72 \mathrm{~h}$. The results of three independent experiments are expressed as means \pm SD. ${ }^{\star} P<0.05 ;{ }^{\star \star} P<0.005 ;{ }^{* \star \star} P$ $<0.0005$.

Figure 1: Protective role exerted by IGF1 in doxorubicin-mediated inhibition of HCC cell growth. 
A

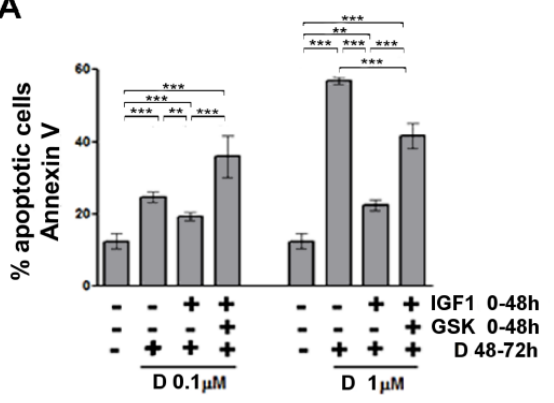

B
C
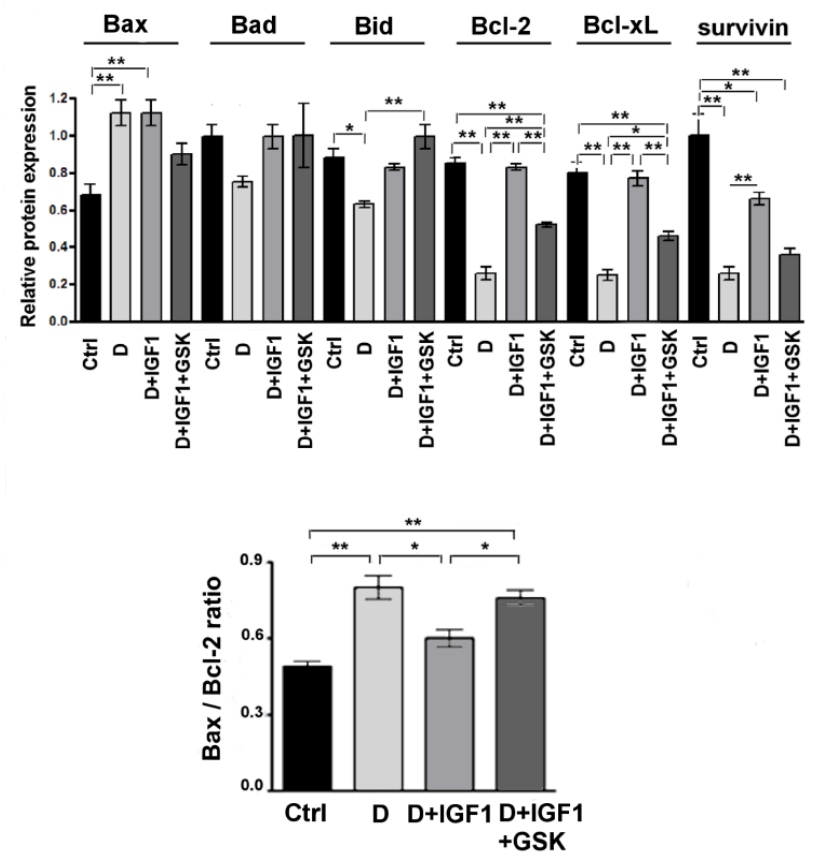

A. PLC/PRF/5 cells pre-treated for $48 \mathrm{~h}$ with $40 \mathrm{ng} / \mathrm{ml} \mathrm{IGF1}$ with/without $1 \mu \mathrm{M}$ GSK1838705A, were next cultured for $24 \mathrm{~h}$ in presence of two different concentrations of doxorubicin (D $0.1 \mu \mathrm{M}$ and $1 \mu \mathrm{M})$. The Muse Annexin $\mathrm{V}$ kit was used to evaluate the percentage of apoptotic cells in three independent experiments. B. Representative Western Blot of pro and anti-apoptotic markers Bax, Bad, Bid, Bcl-2, Bcl-xL and survivin in presence of doxorubicin (D 1 $1 \mu \mathrm{M})$. C. The densitometric analysis of each apoptotic marker, expressed as target protein/actin ratio (arbitrary units) (up) and Bax/Bcl-2 protein ratio (down) in three independent experiments. All results are expressed as mean \pm SD. ${ }^{*} P<0.05$; ${ }^{* *} P<0.005$; ${ }^{* \star *} P<0.0005$.

Figure 2: Protective role exerted by IGF1 in doxorubicin-mediated induction of HCC apoptosis.

we evaluated the phosphorylation levels of ERK and its downstream kinases p-38 and STAT3 after doxorubicin treatment in cells pretreated with IGF1. As shown in Figure 4C, doxorubicin decreased the phosphorylation levels of these proteins and this effect was blocked by IGF1 pre-treatment. All these IGF1 effects were antagonized by $1 \mu \mathrm{M}$ of the IGF1-R inhibitor, GSK1838705A.

\section{Discussion}

Although doxorubicin is a potent cancer chemotherapy drug, its clinical use can be limited by its toxicity and the development of multidrug resistance [3]. The growth of HCC cells and the effects of chemotherapy agents can be modulated by the microenvironmental milieu, including platelets, which can contribute to the stimulation of HCC $[4,6,17,20,21]$. Platelets synthesize several HCC mitogens, some of which have been shown to be involved in chemotherapy drug resistance [22-24]. Among the secreted mitogens, IGF1 plays a role in the hepatocarcinogenic process, and can negatively regulate apoptosis $[11,25]$. Our previous results showed that human platelet lysates (hPLs) could modulate the growth-inhibitory effect of doxorubicin [4]. This effect was due at least in part to the anti-apoptotic action revealed by the induction of anti-apoptotic BcL-xL and survivin levels and the decrease of pro-apoptotic tBid and Bim levels.

Moreover the protective effect of hPL on HCC cell growth was also significant at high doxorubicin concentrations $(1 \mu \mathrm{M})$ [4]. In the present study, we identified IGF1 as a major mediator of the stimulatory effect exerted by hPLs. The involvement of this growth factor was demonstrated by using GSK1838705A, a specific IGF1-R inhibitor, that antagonized the effects of both hPL and of IGF1. Moreover we found a decrease of IGF1-R in doxorubicin-treated cells, but an increase in cells that had IGF1 pre-treatment. Since it has been shown that doxorubicin decreases tumor cell growth, mainly by induction of apoptosis, we focused our investigation on apoptosis and the role of IGF1 [13].

We previously demonstrated that although doxorubicin used at concentration of $\leq 0.1 \mu \mathrm{M}$ weakly affected cell growth, it was effective in long duration of cell treatment [26]. Moreover, we showed that the effect on apoptosis process of these low doxorubicin concentrations was blocked by subsequent hPL treatment [4]. Since doxorubicin concentrations $\geq 1 \mu \mathrm{M}$ can be toxic, in the current experiments, we used two different doxorubicin concentrations $(0.1$ and $1 \mu \mathrm{M})$ and showed that the protective effects of hPLs and of IGF1, were significant even at the higher doxorubicin concentration.

At the lower doxorubicin concentration $(0.1 \mu \mathrm{M})$ the growthinhibitory effect was minimal in both HCC cell lines analyzed and the proliferative rate was completely restored at the control levels by hPLs or IGF1 administration. On the contrary, at the higher doxorubicin concentration $(1 \mu \mathrm{M})$, the strong inhibitory effect was only partially restored by hPLs or IGF1 administration, although in these condition the percentage of antagonism was higher.

Our data showed that IGF1 pre-treatment exerted a significant protective effect in decreasing the percentage of cells in apoptosis in doxorubicin-treated cells, through the activation of survival 
Citation: Refolo MG, D’Alessandro R, Lippolis C, Carella N, Messa C, et al. (2016) Modulation of Doxorubicin Actions in Hepatocellular Carcinoma Cells by Insulin-Like Growth Factor-I. Biochem Anal Biochem 5: 256. doi:10.4172/2161-1009.1000256

Page 5 of 7

A

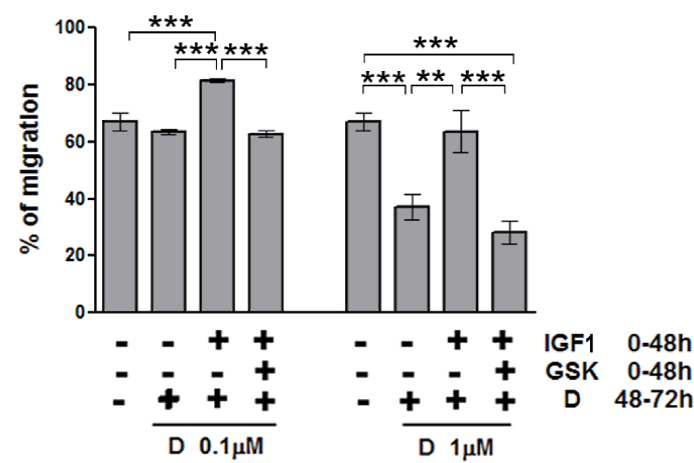

B

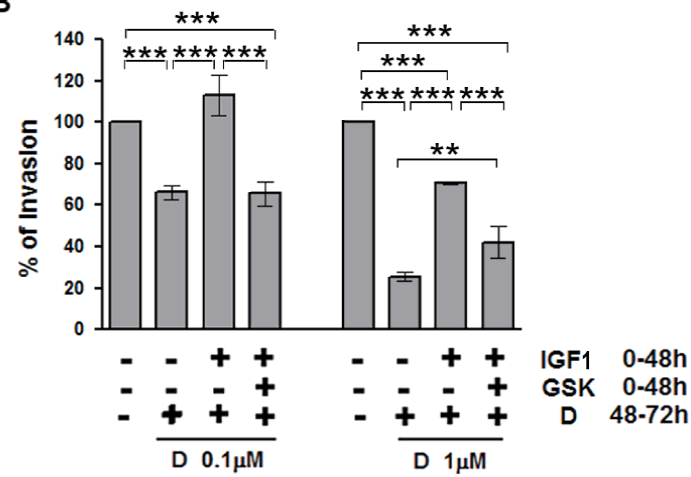

PLC/PRF/5 cells pre-treated for $48 \mathrm{~h}$ with $40 \mathrm{ng} / \mathrm{ml}$ IGF1 with/without $1 \mu \mathrm{M}$ GSK1838705A, were subsequently cultured for the next $24 \mathrm{~h}$ in presence of two different concentrations of doxorubicin (D $0.1 \mu \mathrm{M}$ and $1 \mu \mathrm{M}$ ). A. Migration assay was performed as described in Materials and Method section and the microscopic analysis was assessed at the time of the scratch (T0) and after $48 \mathrm{~h}(\mathrm{~T} 2)$. The values were expressed as percentage of migration, where $100 \%$ represents the scratch completely closed. B. The percentage of invasion was calculated comparing the invading drug-treated cells to drug-untreated control cells $(100 \%)$.

The results of three independent experiments are expressed as means \pm SD. ${ }^{* *} P<0.005 ;{ }^{* * *} P<0.0005$

Figure 3: Protective role exerted by IGF1 in doxorubicin-mediated inhibition of HCC migration and invasion.

pathways. Our results indicate an increase of levels of Bcl-2, Bcl-xL and survivin though the activation of Akt phosphorylated in thr308. PI3K/Akt signaling modulates several downstream pathways. Among these we found a stimulation of mTORC1 by the increased level of phosphorylation of 4EB-P1 and p70S6K. These are involved in protein synthesis and cell growth, as well as a stimulation of glucose metabolism by blocking of GSK-3 $\beta$ that directly regulates Glycogen Synthase activity. Overall these IGF1 effects, antagonizing the doxorubicin action, lead to an increase HCC cell growth.

Recent data correlate platelet counts and the ensuing higher levels of IGF1, with portal vein tumor thrombosis (PVTT) that is a major cause of intra-hepatic metastasis and a major poor prognosis factor for HCC $[27,28]$. Moreover, HCC patients with thrombocytosis are considered at risk for extra-hepatic metastasis [27]. The activation of PI3K/Akt pathway, mediated by IGF1-R, regulates the assembly and re-organization of the actin cytoskeleton and motility by activating $\mathrm{Rac} / \mathrm{Cdc} 42$ [29-32]. We report here findings concerning potential motility in doxorubicin-treated HCC cells, in which the stimulatory role of IGF1 pre-treatment was evident.

Strong antagonism was exerted by IGF1 on the inhibitory effects of doxorubicin on P-ERK and P-p38 levels, as well as on the p38 downstream target, P-STAT3 [4]. These are important molecules in mediating cell proliferation and play a role in the induction of antiapoptosis mediators.

We also found that the IGF1 signaling pathway plays a crucial role in several aspects of cellular biology. The up-regulated IGF1 signaling, causing enhanced cell proliferation and motility and reduced apoptosis, could be considered a major event responsible for drug resistance.

Therefore our results support the idea that IGF1-R might be an excellent molecular target for HCC management [33-35]. For this purpose several preclinical studies based on the use of anti-IGF1-R antiboby [36-38] IGF1-R tyrosine kinase inhibitor [34,39] and RNA

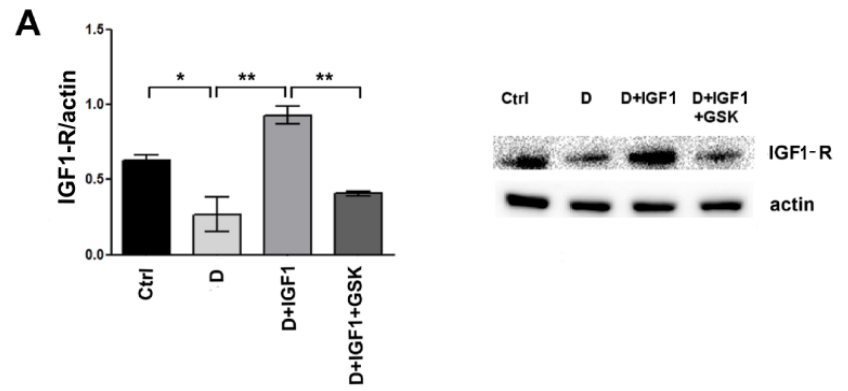

B

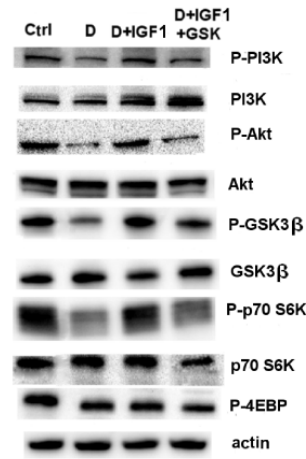

C
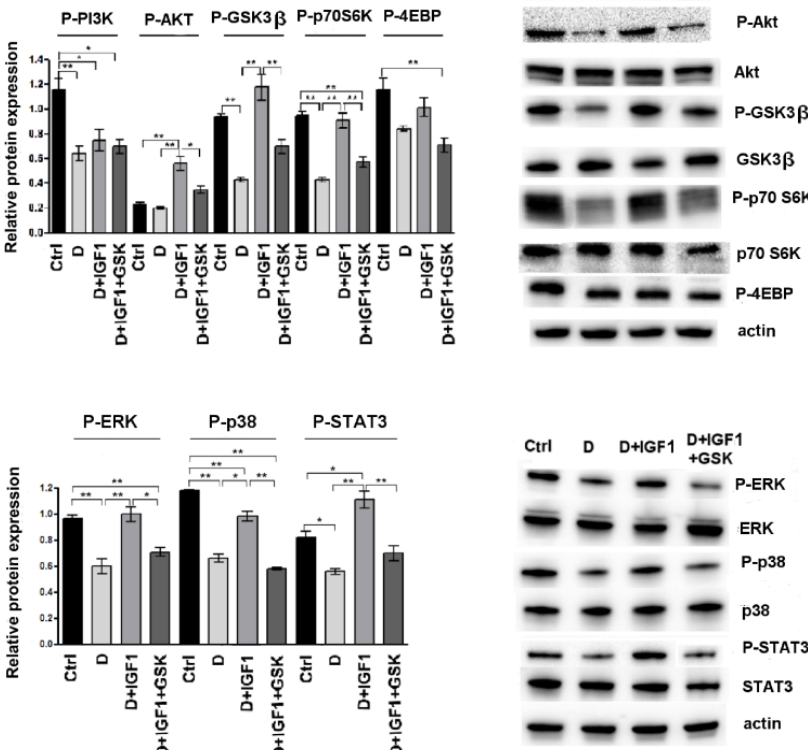

PLC/PRF/5 cells pre-treated for $48 \mathrm{~h}$ with $40 \mathrm{ng} / \mathrm{ml}$ IGF1 with/without $1 \mu \mathrm{M}$ GSK1838705A, were subsequently cultured for the next $24 \mathrm{~h}$ in presence of doxorubicin $(\mathrm{D} 1 \mu \mathrm{M})$. The Western blots analysis indicated the phosphorylation levels of IGF1-R (A) and P-PI3K (tyr458/tyr199), P-AKT (thr308), P-GSK$3 \beta$ (ser9), P-4EB-P1 and P-p70S6K (tyr389) (B) as well as P-ERK (thr202/ tyr204), P-p38 (thr180/tyr182) and P-STAT3 (ser727) (C). The densitometric analysis was performed in three independent experiments. The protein levels were obtained by target protein/actin ratio for IGF1-R and P-4EBP, while by phospho-protein/total protein ratio for all the other proteins.

Representative Western Blots are shown to the right of each panel.

The results are expressed as mean $\pm \mathrm{SD}$. ${ }^{*} P<0.05$; ${ }^{* *} P<0.005 ;{ }^{* *} P<$ 0.0005 .

Figure 4: $\mathrm{PI} 3 \mathrm{~K} / \mathrm{Akt}$ and MAPK signalling modifications due to IGF1 pretreatment in doxorubicin-treated HCC cells. 
Citation: Refolo MG, D’Alessandro R, Lippolis C, Carella N, Messa C, et al. (2016) Modulation of Doxorubicin Actions in Hepatocellular Carcinoma Cells by Insulin-Like Growth Factor-I. Biochem Anal Biochem 5: 256. doi:10.4172/2161-1009.1000256

Page 6 of 7

interference [40] in combination of systemic chemotherapy appear to be promising HCC therapeutic strategies.

There are at least ten IGF1-R inhibitors in clinical trials, but only one, AVE1642, has been assessed for liver metastases [41]. Given our present data about GSK1838705A and the results of others showing the importance of IGF1 in mediating HCC growth and invasion, we think that clinical trials of this class of agent in HCC are warranted.

\section{Acknowledgments}

This work was supported by Italian Ministry of Public Health

\section{References}

1. Lee JY, Han CY, Yang JW, Smith C, Kim SK, et al. (2007) Induction of glutathione transferase in insulin-like growth factor type I receptoroverexpressed hepatoma cells. Mol Pharmacol 72: 1082-1093.

2. Yang F, Chen H, Liu Y, Yin K, Wang Y, et al. (2013) Doxorubicin caused apoptosis of mesenchymal stem cells via p38, JNK and p53 pathway. Cell Physiol Biochem 32: 1072-1082.

3. Wang G, Zhang J, Liu L, Sharma S, Dong Q (2012) Quercetin potentiates doxorubicin mediated antitumor effects against liver cancer through p53/Bcl-xl. PLoS One 7: e51764.

4. Refolo MG, D'Alessandro R, Lippolis C, Messa C, Carella N, et al. (2014) Modulation of Doxorubicin mediated growth inhibition of hepatocellular carcinoma cells by platelet lysates. Anticancer Agents Med Chem 14: 11541160.

5. Hwang SJ, Luo JC, Li CP, Chu CW, Wu JC, et al. (2004) Thrombocytosis: a paraneoplastic syndrome in patients with hepatocellular carcinoma. World $\mathrm{J}$ Gastroenterol 10: 2472-2477.

6. Carr BI, Guerra V (2013) Thrombocytosis and hepatocellular carcinoma. Dig Dis Sci 58: 1790-1796.

7. Miyake H, Hara I, Gohji K, Yoshimura K, Arakawa S, et al. (1998) Expression of basic fibroblast growth factor is associated with resistance to cisplatin in a human bladder cancer cell line. Cancer Lett 123: 121-126.

8. Zhou T, Duan J, Wang Y, Chen X, Zhou G, et al. (2012) Fluoxetine synergys with anticancer drugs to overcome multidrug resistance in breast cancer cells. Tumour Biol 33: 1299-1306.

9. Gooch JL, Van Den Berg CL, Yee D (1999) Insulin-like growth factor (IGF)-I rescues breast cancer cells from chemotherapy-induced cell death-proliferative and anti-apoptotic effects. Breast Cancer Res Treat 56: 1-10.

10. Beech DJ, Perer E, Helms J, Gratzer A, Deng N (2003) Insulin-like growth factor-I receptor activation blocks doxorubicin cytotoxicity in sarcoma cells. Oncol Rep 10: 181-184.

11. Alexia C, Fallot G, Lasfer M, Schweizer-Groyer G, Groyer A (2004) An evaluation of the role of insulin-like growth factors (IGF) and of type-I IGF receptor signalling in hepatocarcinogenesis and in the resistance of hepatocarcinoma cells against drug-induced apoptosis. Biochem Pharmacol 68: 1003-1015.

12. Duan Z, Choy E, Harmon D, Yang C, Ryu K, et al. (2009) Insulin-like growth factor-I receptor tyrosine kinase inhibitor cyclolignanpicropodophyllin inhibits proliferation and induces apoptosis in multidrug resistant osteosarcoma cell lines. Mol Cancer Ther 8: 2122-2130.

13. Martins AS, Mackintosh C, Martín DH, Campos M, Hernández T, et al. (2006) Insulin-like growth factor I receptor pathway inhibition by ADW74, alone or in combination with imatinib, doxorubicin, or vincristine, is a novel therapeutic approach in Ewing tumor. Clin Cancer Res 12: 3532-3540.

14. Scharf JG, Schmidt-Sandte W, Pahernik SA, Ramadori G, Braulke T, et al. (1998) Characterization of the insulin-like growth factor axis in a human hepatoma cell line (PLC). Carcinogenesis 19: 2121-2128.

15. Liang CC, Park AY, Guan JL (2007) In vitro scratch assay: a convenient and inexpensive method for analysis of cell migration in vitro. Nat Protoc 2: 329333.

16. Carr BI, D'Alessandro R, Refolo MG, lacovazzi PA, Lippolis C, et al. (2013) Effects of low concentrations of regorafenib and sorafenib on human HCC cell AFP, migration, invasion, and growth in vitro. J Cell Physiol 228: 1344-1350.

17. Carr BI, Cavallini A, D'Alessandro R, Refolo MG, Lippolis C, et al. (2014)
Platelet extracts induce growth, migration and invasion in human hepatocellular carcinoma in vitro. BMC Cancer 14: 43.

18. Rosendahl AH, Gundewar C, Said Hilmersson K, Ni L, Saleem MA, et al. (2015) Conditionally immortalized human pancreatic stellate cell lines demonstrate enhanced proliferation and migration in response to IGF-I. Exp Cell Res 330: 300-310.

19. Sarkissyan S, Sarkissyan M, Wu Y, Cardenas J, Koeffler HP, et al. (2014) IGF1 regulates Cyr61 induced breast cancer cell proliferation and invasion. PLoS One 9: e103534.

20. D'Alessandro R, Refolo MG, Lippolis C, Giannuzzi G, Carella N, et al. (2014) Antagonism of sorafenib and regorafenib actions by platelet factors in hepatocellular carcinoma cell lines. BMC Cancer 14: 351.

21. D'Alessandro R, Refolo MG, Lippolis C, Carella N, Messa C, et al. (2015) Modulation of Regorafenib effects on HCC cell lines by epidermal growth factor. Cancer Chemother Pharmacol 75: 1237-1245.

22. Radziwon-Balicka A, Medina C, O'Driscoll L, Treumann A, Bazou D, et al. (2012) Platelets increase survival of adenocarcinoma cells challenged with anticancer drugs: mechanisms and implications for chemoresistance. $\mathrm{Br} J$ Pharmacol 167: 787-804

23. Gilbert LA, Hemann MT (2011) Chemotherapeutic resistance: surviving stressful situations. Cancer Res 71: 5062-5066.

24. Tian X, Hao K, Qin C, Xie K, Xie X, et al. (2013) Insulin-like growth factor 1 receptor promotes the growth and chemoresistance of pancreatic cancer. Dig Dis Sci 58: 2705-2712.

25. Pitot HC (1998) Hepatocyte death in hepatocarcinogenesis. Hepatology 28 $1-5$

26. D'Alessandro R, Refolo MG, Lippolis C, Messa C, Cavallini A, et al. (2013) Reversibility of regorafenib effects in hepatocellular carcinoma cells. Cancer Chemother Pharmacol 72: 869-877.

27. Morimoto Y, Nouso K, Wada N, Takeuchi Y, Kinugasa H, et al. (2014) Involvement of platelets in extrahepatic metastasis of hepatocellular carcinoma Hepatol Res 44: E353-359.

28. Aishima S, Basaki Y, Oda Y, Kuroda Y, Nishihara Y, et al. (2006) High expression of insulin-like growth factor bindingprotein-3 is correlated with lower portal invasion and better prognosis in human hepatocellular carcinoma. Cancer Sci 97: 1182-1190.

29. Azuma T, Witke W, Stossel TP, Hartwig JH, Kwiatkowski DJ (1998) Gelsolin is a downstream effector of rac for fibroblast motility. EMBO J 17: 1362-1370.

30. Nobes CD, Hawkins P, Stephens L, Hall A (1995) Activation of the small GTPbinding proteins rho and rac by growth factor receptors. J Cell Sci $108: 225-$ 233.

31. Higuchi M, Masuyama N, Fukui Y, Suzuki A, Gotoh Y (2001) Akt mediates Rac/ Cdc42-regulated cell motility in growth factor-stimulated cells and in invasive PTEN knockout cells. Curr Biol 11: 1958-1962.

32. Welch HC, Coadwell WJ, Stephens LR, Hawkins PT (2003) Phosphoinositide 3-kinase-dependent activation of Rac. FEBS Lett 546: 93-97.

33. Zhang YW, Yan DL, Wang W, Zhao HW, Lu X, et al. (2012) Knockdown of insulin-like growth factor I receptor inhibits the growth and enhances chemosensitivity of liver cancer cells. Curr Cancer Drug Targets 12: 74-84.

34. Pollak M (2008) Insulin, insulin-like growth factors and neoplasia. Best Pract Res Clin Endocrinol Metab 22: 625-638.

35. Pollak M (2008) Targeting insulin and insulin-like growth factor signalling in oncology. Curr Opin Pharmacol 8: 384-392.

36. Zhang YC, Wang XP, Zhang LY, Song AL, Kou ZM, et al. (2006) Effect of blocking IGF-I receptor on growth of human hepatocellular carcinoma cells. World J Gastroenterol 12: 3977-3982.

37. Bauer TW, Fan F, Liu W, Camp ER, Yang A, et al. (2007) Targeting of insulinlike growth factor-I receptor with a monoclonal antibody inhibits growth of hepatic metastases from human colon carcinoma in mice. Ann Surg Oncol 14: 2838-2846.

38. Esparís-Ogando A, Ocaña A, Rodríguez-Barrueco R, Ferreira L, Borges J, et al. (2008) Synergic antitumoral effect of an IGF-IR inhibitor and trastuzumab on HER2-overexpressing breast cancer cells. Ann Oncol 19: 1860-1869. 
Citation: Refolo MG, D'Alessandro R, Lippolis C, Carella N, Messa C, et al. (2016) Modulation of Doxorubicin Actions in Hepatocellular Carcinoma Cells by Insulin-Like Growth Factor-I. Biochem Anal Biochem 5: 256. doi:10.4172/2161-1009.1000256

Page 7 of 7

39. Höpfner M, Huether A, Sutter AP, Baradari V, Schuppan D, et al. (2006) Blockade of IGF-1 receptor tyrosine kinase has antineoplastic effects in hepatocellular carcinoma cells. Biochem Pharmacol 71: 1435-1448.

40. Niu J, Qian HX, Li XN, Han ZG (2007) Inhibitory effect of IGF1R siRNA on the growth of human liver cancer SMMC7721 cell xenograft in nude mice. Ai Zheng 26: 703-708.

41. Chen HX, Sharon E (2013) IGF-1R as an anti-cancer target-trials and tribulations. Chin J Cancer 32: 242-252. 